\title{
Cultura e Memória: percepções das lembranças re-existentes no tempo ${ }^{1}$
}

\author{
ALESSANDRA LEAL \\ Mestre em Geografia pela Universidade Federal de Uberlândia e pesquisadora do Grupo de Estudos e \\ Pesquisas do Rio São Francisco Ï OPARÁ.
}

RESUMO: Este escrito é um exercício reflexivo sobre duas categorias de pesquisa e de vida: memória e cultura. Durante todo o ano de 2010 estive entre leituras, re-leituras, vivências e escritas sobre cultura. Vivenciei de perto os caminhos que movimentam o nascer e o desenvolver de um ato cultural. A memória até então tinha sido não apenas pano de fundo, mas ícone tratado e não detalhado. Agora, relendo textos e autores descubro dizeres não percebidos antes, percebo uma fala e uma descrição que perpassa por tempos passados, presentes para alcançar futuros e que não apenas dizem de um e de um coletivo, mas de um que passa por vários para se tornar o coletivo, para se tornar o que é uma memória coletiva, constituída por vivências assomadas. Constituída por memórias-hábitos, memórias-percepção que se tornam ou são atos de uma cultura. Descubro que memórias são baús vivos e fluídos de lembranças formadas por existências no aqui e agora. Aqui e agora por sua vez que se alicerçam num tempo passado, ou seja, no re-existir de atos, agires e saberes que são o acesso ao baú de lembranças, à memória. Desse descobrimento, me movo a refletir, compartilhando com você caro leitor, os entre - laços que tecem memória, memórias e cultura, culturas. Nossas leituras passarão por autores como Éclea Bosi, Maurice Halbwachs, Carlos Brandão, Terry Eagleton, Michel de Certeau e Raymond Williams.

PALAVRAS-CHAVES: memória, cultura, lembranças

RESUMÉ: Cette écriture est un exercice de réflexion sur les deux catégories de recherche et de la vie : la mémoire et la culture. Tout au long de l'année 2010 a été entre les lectures, relectures, des expériences et des écrits sur la culture. J'ai vécu de près les manières qui se déplacent à la naissance et le développement d'un acte culturel. Mémoire jusqu'alors pas seulement une toile de fond, mais l'icône n'est pas traitée et détaillées. Maintenant, les textes et les auteurs relecture trouver des mots pas perçue avant, je vois un discours et une description qui imprègne le passé, le présent et l'avenir de réaliser non seulement un droit de regard et d'un collectif, mais qui passe à travers pour devenir plus le collectif, pour devenir ce qui est une mémoire collective, composée d'expériences Assomada. Composée de souvenirs, d'habitudes, les perceptions, les souvenirs qui deviennent ou sont des actes d'une culture. Je trouve que les souvenirs sont des troncs fluide et vivante de souvenirs formé par les stocks dans l'ici et maintenant. Ici et maintenant, à son tour qui se fondent dans un temps passé, c'est la réagit existent, agissent et les connaissances qui sont l'accès à la poitrine de souvenirs et la mémoire. De cette découverte, je propose de réfléchir, de partager avec vous, cher lecteur, entre le - des liens qui tissent la mémoire, les souvenirs et la culture, les cultures. Nos lectures Bosi Ecléa par des auteurs comme Maurice Halbwachs, Carlos Brandao, Terry Eagleton, Michel de Certeau et Raymond Williams.

${ }^{1}$ Texto escrito com apoio de Bolsa de Apoio Técnico do CNPq, vinculado ao Grupo de Estudos e Pesquisas do Rio São Francisco Ï OPARÁ por intermédio do projeto Etno-cartografias do São Francisco: modos culturais de vida cotidiana, culturas locais e patrimônios culturais em/de comunidades tradicionais no Norte de Minas Gerais, também financiado pelo CNPQq 478988/2009-5. 
MOTS-CLÉS: memoire, culture, souvenir

\section{Pensando memória}

Cultura e memória ou memória e cultura? Parece uma pergunta boba do tipo quem você quer pão com manteiga ou manteiga com pão?, Mas, a ordem dos fatores com certeza altera o produto. Até na pergunta do pão com manteiga. A memória, como baú vivo e fluído de guardados, imagens, de lembranças, são nossas referências. É o baú onde está guardado o conhecimento construído de nossos ancestrais. Não só porque ouvi de minha mãe que ouviu de minha avó, que ouviu de minha tataravó, mas, também porque repito de diferentes formas esse conhecimento, porque compartilho de diferentes formas e ele se enraíza nos viveres dos meus. ñA memória é a reserva que se dispõe da totalidade de nossas experiênciasò (BOSI, 1979. p. 13).

Com isso quero dizer que minhas memórias não dizem só de mim, mas, retomam nos meus agires o que foi vivido por meus ancestrais e o que vivo com meus entes, amigos, irmãos, tios, pais, conhecidos virtuais ou amigo do meu amigo quando ouço sua história contada por esse amigo. É o que Halbawachs vai chamar de memória coletiva. A memória que re-existe as experiências não só do individuo, mas do seu grupo.

A memória por meio das lembranças tece e fortalece relações que de tão cotidianas e banais passam despercebidas no dia-a-dia. Quando conto para minha irmã mais nova o que aconteceu na escola, quando falo que respondi com paciência e carinho a seriedade e braveza de um colega zangado por ter tido um relógio quebrado, não conto só que eu tive a paciência e compreensão de entender a chateação e prejuízo que ele teve, mas carrego nas entrelinhas que aprendi agir assim com a experiência que tenho vívida em mim e trazida ou por meus pais ou por outros amigos. Seja essa experiência apreendida na corrente, ou seja, na mesma paciência e compreensão; seja na contracorrente, ou seja, quando vejo nos meus pais ou naquele amigo que a incompreensão e a impaciência não são o melhor caminho para o bem estar e a harmonia para com as pessoas que estão no convívio.

A essa forma de guardar lembranças Halbwachs (2006) chamou de memória individual, ou seja, a forma como seleciono e disponho as imagens-lembranças vividas, ou a forma como as organizo internamente em todo o conjunto de referências e memórias-hábitos (que constituí a memória coletiva) aprendidas. A memória individual é a partícula do đ́uôna memória coletiva. É a subjetividade dos detalhes, dos objetos e das construções dos cenários, das imagens, é a forma como a imagem é revelada que caracterizam a individualidade da memória, pois, diz da história pessoal e da vivência do indivíduo. A atenção que dou a fita vermelha nos meus cabelos, ou ao dedo do pé machucado do menino que atravessava a rua, são detalhes que dizem das experiências que eu vivenciava em meio a todo o contexto do coletivo.

As lembranças podem ainda serem guardadas na memória de uma forma tão singela que passam despercebidas num primeiro momento ao consciente. Por exemplo, no cozer arroz, que vejo e sou orientada por um outro, que repito e repito e repito até fazer sem ver (que me lembro) que sei fazer, sem ver que me lembro (que acesso a memória-hábito). Outras são marcadas por fatos, seja um festejo aonde ouço tambores ritmados e vejo danças com fitas, seja por uma contação de estórias em que ouço 
experiências de um mundo de fantasias ou de histórias vividas por um alguém próximo. Mais tarde, serão acessadas para seguirem se presentificando no futuro, quando eu, que ouvi e vivi, a contar a meus filhos e netos.

O que foi aprendido fica guardado, na memória, e é acessado pela memóriapercepção e é perpetuado pela memória-hábito. Eu aprendo, compreendo, armazeno e acesso por meio da percepção consciente inúmeras e incontáveis vezes a referência armazenada e coloco-a em prática, na ação por meio do hábito, do condicionamento. Posso inclusive recontar a primeira experiência, aquela que ficou como palavra-chave para o que é acessado e condicionado, como história, como lembrança que me vêm à mente por meio de imagens. Imagens daquele acontecer que ou foi na corrente ou na contra-corrente. ñNa realidade, não há percepção que não seja impregnada de lembrançasò (BERGSON apud BOSI, 1979. p.08)

\begin{abstract}
De um lado, o corpo guarda esquemas de comportamentos de que se vale muitas vezes automaticamente na sua ação sobre as coisas: trata-se da memória-hábito, memória dos mecanismos motores. De outro lado, ocorrem lembranças independentes de quaisquer hábitos: lembranças isoladas, singulares, que se constituíram autênticas ressurreições do passado. (BERGSON apud BOSI, 2003. p.39)
\end{abstract}

A memória-hábito se aproxima intimamente das lembranças por serem marcadas pelos traços que as armazenam na memória. Traços do vivido, do que aconteceu em ações presentes na linha do tempo. É o que o tornam também presentes, de fácil acesso na memória e reais enquanto imagens acessadas. O que não acontece, por exemplo, com as lembranças dos sonhos. Estas são efêmeras e fugidias por não terem se materializado no acontecido, no espaço e tempo. ñQuanto mais pessoal, mais livre, menos socializada, menos presa a ação presente for a lembrança, mais distante, rara e fugitiva será a sua atualização pela consciênciaò. (BOSI, 1979. p.17). É comum lembrarmos vagamente de fleches de imagens-sonho que são freqüentemente esquecidas em seguida, quando não associadas à outras lembranças-imagens acontecidas no espaço tempo.

ñA lembrança é a sobrevivência do passadoò. (BOSI, 1979. p.15). É por meio dela que o passado é recontado e perpetuado. É por meio dela que nossas reflexões, nossas descobertas filosóficas se alicerçam. É revendo imagens de uma história vivida ou ouvida que transmito ao outro o conhecimento construído por mim na vivência. ñA memória permite a relação do corpo presente com o passado e, ao mesmo tempo, interfere no processo átualô das representações (BOSI, 1979. p.09) Estando no presente, volto ao passado para transformar em imagens a mensagem a ser transmitida, junto à emoção e sensações que acompanharam o vivido ou que são re-significados no momento presente.

Uma lembrança é diamante bruto que precisa ser lapidado pelo espírito. Sem o trabalho da reflexão e da localização, seria uma imagem fugidia. O sentimento também precisa acompanhá-la para que ela não seja uma repetição do estado antigo, mas uma reaparição. (BOSI, 1979. p. 39)

É pela lembrança ainda que recriamos o presente, que fugimos do instante sofrido, assustador e insuportável para aconchegarmos em imagens, em tempos de alegria e bem estar. É o momento em que lembranças e histórias se tornam também curadoras. A criança que ouve o contar, que recebe imagens vividas em outros tempos se energiza, tranquiliza e alcança o sono, mesmo em meio a angustia da doença. Isso acontece com jovens, adultos e velhos também. É comum em leitos de hospitais, 
instintivamente parentes lembrarem de tempos e histórias de vivências em comum. É uma forma do corpo buscar em si mesmo, em imagens do saudável referências, imagens para lembrar o próprio corpo de que ele pode retornar àquele estado de graça.

A narrativa é terapêutica, apressa a convalescença quando a mãe, sentada junto ao leito da criança, desperta-lhe outra vez o gosto pela vida. Concordo, porque a história contada é um farmacon, antes preparado pela narradora nos tubos e provetas da fantasia e da memória, através de sábia dosagem. (BOSI, 2003. p.10)

Essas mesmas lembranças, que ficaram guardadas pelo caminho do consciente claro, podem se tornar, também em recordações. Podem ser acessadas e recontadas de diferentes formas. São imagens que podem ser transformadas e readequadas de acordo com o conjunto de referências do presente. Assim a estória que foi contada e que aos nove anos eu recontava dando destaque e atenção ao Papai Noel que entreva presentes é recontada com atenção aos risos e impressões que tive na época e que trazem a lição projetada na mesma. A recordação em outras palavras é a forma fluída de organizar e reorganizar as memórias num tecer entre passado (memória) e presente (novas referências, novas vivências). Num acessar as lembranças que mais que guardadas na memória, são tocadas pelo coração.

Recordar, lembrar e, portanto, a memória é também lócus de compartilhamento entre pessoas e grupos em pelo menos dois momentos: o instante em que os fatos, a história acontece e os instantes em que serão recordados depois. ñA memória é, sim, um trabalho sobre o tempo, mas sobre o tempo vivido, conotado pela cultura e pelo indivíduo.ò (BOSI, 2003. p. 53). Afinal, o que vivo, vivo de acordo com lembranças, memórias-hábito, condicionamentos e aprendizados culturais transmitidos e a mim ensinados por outros que vem de outros tempos. E o que escolho como essencial para que fique ao alcance da memória consciente é também influenciado por todo o contexto cultural e comunitário a que estou exposto.

Ecléa Bosi em dois de seus livros, (Memória e Sociedade: lembranças de velhos e $O$ Tempo vivo da memória: ensaios de Psicologia Social) faz uma leitura a teorização de Prost Bergson ${ }^{2}$ sobre o cone da memória. Nele Bergson comenta:

Se eu represento por um cone $\mathrm{SAB}$ a totalidade das lembranças acumuladas em minha memória, a base $\mathrm{AB}$, assentada no passado, permanece imóvel, ao passo que o vértice $\mathrm{S}$, que figura em todos os momentos o meu presente, avança sem cessar e sem cessar, também, toca o plano móvel $\mathrm{P}$ de minha representação atual do universo. Em $\mathrm{S}$ concentra-se a imagem do corpo; e, fazendo parte do plano $\mathrm{P}$, essa imagem limita-se a receber e a devolver as ações emanadas de todas as imagens de que se compõe o plano. (BERGSON, apud BOSI, 1979. p.10)

\footnotetext{
${ }^{2}$ No livro: Matière et Mémoire. Ouvres, Paris: PUF, 1959.
} 


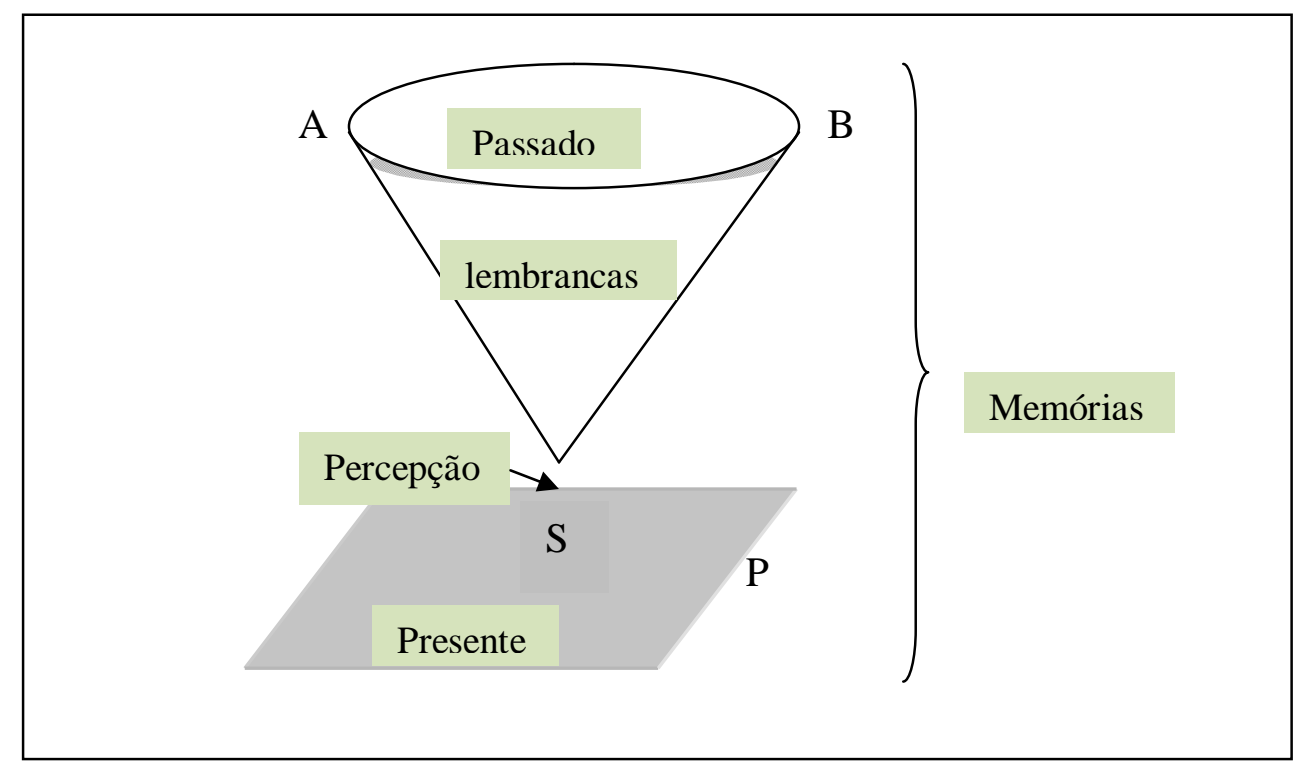

Tentando digerir a informação, leríamos o interior do cone como lembranças, o círculo inicial como passado, a ponta do cone (S) como a memória-percepção, ou seja o ato de acessar o passado e lembranças, sendo influenciadas pelo contexto e instante do presente. $\mathrm{O}$ plano $\mathrm{P}$, seria o presente, o instante que re-significa e reconfigura imagens e cenas acessadas pela percepção. Percepção e presente se entrelaçam para trazer o que já foi presente para a cena num exercício que dá vida e movimento ao que estava estático (passado). Essa é em si uma característica da memória, promover fluidez e vida ao que num primeiro momento parece acabado e pronto.

O que aprendo e o que escolho enquanto importante e significativo para ser recontado enquanto referência, faço-o enquanto indivíduo socializado, enquanto indivíduo condicionado (no sentido de aprendizado já internalizado, como lavar pratos ou dirigir um veículo), é delineado pelas lembranças, pela memória não só minhas, mas do grupo a que faço parte. Já que o que lembro e o que define minhas memórias são em parte trechos e recordações da memória desse mesmo grupo.

A memória do individuo depende do seu relacionamento com a família, com a classe social, com a escola, com a Igreja, com a profissão; enfim, com os grupos do convívio e os grupos de referências peculiares a esse individuo. (...). A menor alteração do ambiente atinge a qualidade íntima da memória. (BOSI, 1979. p.17).

É esse ciclo que permite perpetuar no tempo conhecimentos, aprendizados, práticas, saberes e agires que caracterizam cada grupo e que ao longo do seu re-existir numa linha temporal se torna tradição, se torna cultural, transforma-se na identidade também definidora do grupo ou comunidade. É assim, que talvez uma Folia de Reis reexiste de geração em geração, quando a lembrança e a relação do tempo e lembrança, é transmitida de pai para filho e de filho para neto.

A memória coletiva que diz da cultura, do viver de um grupo, se baseia na semelhança, no que há em comum nas minhas e nas suas lembranças, num período do tempo. É ela que vai dizer do semelhante, do que acontece em comum entre os viventes da comunidade. Assim, a memória que é coletiva torna-se também tradição. E ao se 
tornar tradição conta as memórias não só de um sujeito, mas de um grupo, de uma comunidade, de uma cidade, de uma região, de um país, de um continente, de um planeta. Assim contamos a história-memória de toda a humanidade. Assim, acessamos e construímos a memória-histórica (memória que reconstrói os fatos da vida cotidiana projetada sobre o passado) de grupo por grupo até chegarmos à do homo-sapiens. (HALBWACHS, 2006). A memória histórica olha as mudanças, as transformações que acontecem na linha do tempo, pois, são elas que marcam, que destacam fatos e datas. É a partir delas que se conta o início, o meio e o fim

\begin{abstract}
A criança recebe do passado não só os dados da história escrita; mergulha suas raízes na história vivida, ou melhor, sobrevivida, das pessoas de idade que tomaram parte na sua socialização. Sem estas haveria apenas uma competência abstrata para lidar com os dados do passado, mas não a memória. (BOSI, 1979. p.31)
\end{abstract}

Dessa forma, a memória é construída com base na vivência do agora. Os sentimentos, as impressões, as sensações e as idéias que me toma num dado momento vão direcionar tanto o desenrolar do aqui e agora, que se tornarão imagens-lembranças, quanto delinearão as imagens-lembranças que acessarei, assim como ainda as novas impressões que elas me despertarão. É o presente se sobrepondo ao passado, é o individual se pronunciando no coletivo.

Coletivo que por sua vez se constrói na junção de espaços, lugares, e referências compartilhadas. Estas já foram aqui descritas como memórias-hábito, como memóriascoletivas que são re-existentes na linda do tempo. Mas, o que são as memórias, o que elas carregam em suas imagens e repetições? Entendemos que esse conteúdo transportado e que re-existe continuamente são nossos traços culturais, são nossos atos e agires, nossos saberes e fazeres culturais e que se transformam cada vez mais rapidamente à medida que as memórias dos grupos dialogam e se misturam.

\footnotetext{
É a essência da cultura que atinge a criança através da fidelidade da memória. Ao lado da história escrita, das datas, da descrição de períodos, há correntes do passado que só desaparecem na aparência. E que podem reviver numa rua, numa sala, em certas pessoas, como ilhas efêmeras de um estilo, de uma maneira de pensar, sentir, falar, que são resquícios de outras épocas. Há maneiras de tratar um doente, de arrumar camas, de cultivar um jardim, de executar um trabalho de agulha, de preparar um alimento que obedecem fielmente os ditames de outrora. (BOSI, 1979. p.33 ï grifos nossos)
}

A memória é o fio condutor em que a cultura é transportada pelos tempos. É ela que nos permite a consciência de estarmos no presente e de já termos vivido um antes. É ela que nos permite a noção do tempo e por meio dela prosseguimos na linha de sucessões e de aprendizados compartilhados.

\title{
Pensando Cultura
}

Em minhas primeiras leituras a cultura aparecia como algo extremamente abstrato e paradoxal. Algo que variava entre o que seria quase natural e espontâneo, até o que era criado e modificado pelo homem, de forma motivada e sistêmica, em sua ação sobre a natureza. 
Devemos reconhecer que uma polarização da própria idéia de cultura, indo de um extremo a outro, ao mesmo tempo em que amplia o debate e o abre a diferentes concepções, dificulta enormemente uma compreensão do que ela possa significar. Eisnos diante de um conceito científico que oscila entre a centralidade em algumas teorias e a marginalidade em outras.

Assim, nosso ponto de partida poderia estar no pensar a cultura como sendo a interação entre um modo de vida, as formas dadas a ele e os símbolos que certo grupo cria e vivência em seu dia a dia. Formas e símbolos que são reconhecidas não apenas entre os seus participantes, mas, em alguma medida, por outros grupos que vivem e se manifestam culturalmente de forma diferente. (WILLIAMS, 2008).

Podemos lembrar na idade média, nas viagens, incursões e guerras, em que os bárbaro-civilizados do ocidente ádesbravavamôa ferro e fogo novas terras, descobrindo assim outros modos de vida entre religiões e iguarias. Ou reportarmo-nos à expansão marítima, ao descobrimento das Américas, quando as ocas e a vida silvícola eram apontadas como algo que existe entre o selvagem e o primitivo. O r̃bom selvagem ${ }^{3}$ ò e ñmau civilizadoò, o ñmau civilizadoòe o ñbom selvagemò mesclam as visões culturais daquela época, ou de épocas passadas, quando, ao se perceber o outro, e no outro, as pessoas e as culturas de então pensavam como desigualdades e de culturas o que hoje pretendemos compreender como diferenças entre culturas.

Questiono então: como surge essa distinção, esta diferença? Como se estabelecem sistemas de símbolos, de sentidos, de significados e de valores tão diferentes entre povos distintos? Em um primeiro momento, pela relação que o homem estabelece com a natureza. Nos primórdios da organização humana, as criações culturais surgem como alternativas de respostas diante das dificuldades e limitações de recursos e dos espaços naturais. É tentando caçar que o homem afia a pedra; é para matar que esculpe a ponta da madeira, e é para cortar a carne do animal que surge a face de pedra e, depois, a faca de ferro amolada. É para se abrigar das intempéries climáticas que o homem constrói habitações. Assim se iniciam as transformações de coisas da natureza em objetos da cultura material. Artefatos e instrumentos que vão ganhando adequações ao longo da história de cada grupo cultural humano, ora para melhoria, ora para embelezamento do objeto. Pois desde os primórdios da sua trajetória na terra, ao se espalharem pelos mais diversos ambientes naturais do planeta, os diferentes grupos humanos tiveram que encontrar soluções diversas para fazer frente aos mesmos problemas.

Assim, ña natureza produz cultura que modifica a naturezaò. (EAGLETON, 2005. p.12). Objetos naturais, como pedra, madeira e barro transformam-se utilitariamente para, em seguida, se re-significarem semanticamente, gerando, complexificando e transformando os códigos de conceitos, valores e sentidos do humano. Eis o que em boa medida aos poucos delineia formas de organizações e modos de viver característicos de um grupo humano social, e as diferenças entre ele e outros.

O processo social de criação de cultura é o que atribui ao ser humano a possibilidade de afirmar-se como um ser com consciência a respeito do seu saber. Enfim, como um sujeito que habita de modo singular a sociedade e constrói uma história. (BRANDÃO, 2009. p.54)

3 Referência à LAPLANTINE, François. Aprender Antropologia. 9a edição. São Paulo, Editora Brasiliense. 1996 
O homem modifica a natureza em busca de segurança, de alimento e proteção. A busca da reprodução de seu grupo físico e social, e as maneiras diversificadas como ele maneja diferentes sistemas da natureza, promovem o plano mais substantivo e material de nossas diferenças culturais. Assim, podemos pensar que um grupo que vive a beira mar, desenvolve alternativas diferentes de outro que vive no sertão. E mesmo grupos próximos, diante de recursos à vista diversos, criam estratégias culturais também diferentes. $\tilde{\mathrm{n}}(. .$.$) nós transformamos os ambientes em que vivemos para adaptá-los a nós$ e para tornarmos possíveis e progressivas as nossas vidas nelesò. (BRANDÃO, 2008: 27).

\begin{abstract}
A comunicação das consciências é condição de existência da cultura como dado objetivo $і ̈$ algo que existe mais além da pura subjetividade individual, no interior da vida coletiva ï por ser o que permite a existência de símbolos, valores e bens culturais, transmitidos e co-participados. (BRANDÃO, 2009. p.57-58).
\end{abstract}

Tais adaptações e inovações são compartilhadas entre os membros de um grupo. Um grupo humano que se uniu socialmente como uma alternativa cultural para a sua sobrevivência. E que pelo mesmo motivo seus integrantes mantêm relações de trocas e de auxílios mútuos. Esta conduta original e suas derivadas terão sido o ponto inicial para o surgimento de dimensões da cultura. À diferença dos animais, os seres humanos, ao transformarem a natureza, transformam-se a si mesmos. Eles não surgem no mundo biologicamente equipados para viverem em coletividades. Assim, eles precisam aprender a criar culturalmente as sociedades em que vivem.

Portanto, ao mesmo tempo em que agem sobre o mundo natural transformandoo, agem sobre si próprios, transformando-se. Atuam sobre as coletividades que criam para poderem, co-existindo, sobreviver no plano individual e no plano coletivo. Macacos de uma mesma espécie possuem uma forma única de coletividade. Os seres humanos são capazes de, vivendo em um mesmo ambiente natural, criar várias formas diferentes de associações, de sociedades e de suas vidas socioculturais.

Em uma outra dimensão, ainda, os seres culturais que nós somos desenvolveram diferentes alternativas do ensinar e aprender, do aprender os saberes, os significados, os valores, enfim as gramáticas sociais de seu mundo cultura, através de formas várias de educação.

Aqui podemos visualizar o conhecido ñensinamento tradicionalò, em que os mais velhos contam estórias de uma vida antiga, seus costumes, suas raízes de identidade. Estórias, que se iniciam como histórias, como o contar acontecimentos de gerações anteriores que, com o passar do tempo, ganham novos símbolos e elementos, tornando-se estórias, às vezes lendas, às vezes mitos, às vezes ritos.

As crianças, atentas, ouvem e internalizam por meio dos símbolos e significados ali contidos, os mitos, as façanhas, mas também os conceitos, os princípios culturais da vida social e os seus valores. ñPráticas do fazerò, ñéticas do agirò, ñógicas do pensarò que serão importantes para a vida na sociedade e que, por este motivo, será por ela ensinado de uma para outra geração. O aprender, aliado ao transformar contínuo e ao transmitir o saber. O aprender e o transformar a si mesmo e ao outro que possibilitou que ao longo da sua história o homem multiplicasse formas de criação de mundos 
sociais, as suas modificações e a sua transmissão de uma a outra geração, através do aprendizado. Na verdade, ñcada um de nós, recapitula essa história em sua biografiaò. (BRANDÃO, 2008. p.28.). A diversidade criativa e, portanto, cultural, se espelha e espalha na e através da diversidade biológica e natural.

Dessa forma, não só transformamos a pedra em instrumentos de corte, como aprendemos a extrair metais e a fabricar facas cada vez mais afiadas. E com o próprio desenvolver da cultura, não só criamos facas afiadas, mas, aprimoramos a forma de extração dos minérios, na medida em que descobrimos alternativas cada vez mais otimizadas de fabricação das ferramentas, como mesmo a produção de minerais sintéticos. É o natural que se transforma no artificial. É ño que fazemos ao mundo e o que o mundo nos fazò (EAGLETON, 2005. p.11). Uma transformação da natureza tão altamente elaborada chega em nossos dias a ultrapassar a fronteira do utilitário e necessário, e se desdobra até o ponto de acarretar um outro sistema que nos traz como conseqüência a sobrecarga de produtos desnecessários e a exploração da força de trabalho.

Observamos no cotidiano a substituição incessante de pessoas por objetos e coisas. Afirmamos que no meio de tudo isso, entre o artificial e o natural, foi e é a cultura o substrato através do qual a espécie humana passa da sua dimensão de natural ánimalidadeô para a organização complexa e extremamente simbólica em que se transformou ao longo das eras e em que se encontra hoje. Portanto, é a cultura que nos faz conviver e interagir com o mundo, com os nossos outros e com os símbolos, saberes e significados que criamos e partilhamos, entre o ânimo e desanimo, entre esperança e fadiga, entre possibilidade da destruição do mundo natural e da humanidade, e a esperança do desenvolvimento humano e do incremento da vida.

A cultura realiza-se através de uma dialética que surge do trabalho com as mãos e se amplia rapidamente numa produção mecânica, produzindo nesse entremeio dualidades entre o mais próximo e o mais distante do natural e da natureza. Entre um modo de vida que se mantém próximo àquele dos primeiros passos culturais, em que a participação, o compartilhamento e as relações solidárias são mantidas. E outros ómodernizadosôe transformados, nos quais o individualismo, o funcional, o utilitário e o industrial são predominantes.

Ela até alude ao contraste político entre evolução e revolução ï a primeira, órgânicaôe áspontâneaô a última, artificial e forçada ï e também sugere como se poderia ir alem dessa antítese. A palavra combina de maneira estranha crescimento e cálculo, liberdade e necessidade, a idéia de um projeto consciente, mas, também de um excedente não planejavel. (EAGLETON, 2005. p.14)

Tudo isto porque a cultura não se esgota apenas na dimensão instrumental e mecânica de nossos relacionamentos com a natureza. Ao contrário, tais complexos relacionamentos são possíveis porque somos seres do símbolo, do sentido e do significado. Somos seres que no mesmo momento em que tomam algo da natureza, como uma pedra e a transformam em um utensílio, atribuem à pedra, ao utensílio e ao gesto que transforma a pedra em utensílio, um teor E um valor simbólico.

Assim, criando e transmitindo saber, criando e compartilhando símbolos e significados, perpetuamos a cultura e as culturas. Criamos um mundo humano e, no seu interior, diferenciamos múltiplos mundos culturalmente diferentes e diferentemente 
socializados. óMundosô que surgem com a criação e o compartilhamento. Mundo e mundos sociais em que o todo está no um, no uno, como quando alguém reproduz condutas aprendidas e age culturalmente de uma forma que através de suas diferenças culturais representa também um universal da espécie humana. Um mundo humano, enfim, em que tudo está no todo, no sistema social de relações e trocas entre pessoas, entre grupos de pessoas e entre unidades sociais maiores e mais complexas.

A sociedade que surge através da luta humana pela sobrevivência e se perpetua no simbólico, tende a transformar-se e vai se complexificando com o desenrolar dos mais diferentes sistemas de relações inter-individuais que envolvem permanentemente trocas e reciprocidades entre pessoas, coisas e mensagens. Todo um sistema social de condutas e comportamentos é estabelecido e configurado através de círculos que vão da biografia individual a toda a história de um povo. E cada biografia sempre será parte de um emaranhado de historias de outros e outras que geram e compõem a biografia de cada um e uma. Em que um pai ensina o seu filho que ensina seu filho em uma cadeia de trocas e saberes através de um contínuo ensinar-e-aprender. ñCada ser humano é um eixo de interações de ensinar-aprender. Assim, qualquer que seja, cada pessoa é em si mesma uma fonte original de saber e de sensibilidade.ò (BRANDÃO, 2008. p. 33) É o educar que perpetua a espécie humana numa dependência do homem pelo próprio homem, ou pelo outro homem.

Um ator social que aprende os óaberesônecessários para sua própria existência, internaliza os conceitos, os valores e as normas através da experiência e, também, com a repetição do comportamento de um outro com o qual aprende. Á medida que o grupo de pessoas permite e incentiva este fenômeno, acontece à socialização. E ela é o aprendizado consciente e inconsciente do código cultural pelos que chegam a um mundo social. E, claro, a socialização se dará de acordo com os padrões sociais de um dado grupo cultural e da sociedade em que está inserido. Ele preserva e transmite padrões sociais, ou seja, as normas, regras, crenças, valores são propostos e impostos à conduta individual do que aprende. E dessa forma, o círculo de ensinar e aprender, de transmitir traços e expressões culturais alça vôos por gerações e grupos incontáveis. Círculo que nasce na interdependência humana e se eterniza nas relações e experiências culturais.

A cultura está contida em tudo e está entretecida com tudo aquilo em que nós nos transformamos ao criarmos as nossas formas próprias ï simbólicas e reflexivas $\ddot{i}$ de convivermos uns com os outros, em e entre nossas vidas. Vidas vividas, de um modo ou de outro, dentro de esferas e domínios de alguma vida social. (BRANDÃO, 2008. p. 31)

Entre outros vários autores, Peter Berger e Thomas Luckman ${ }^{4}$ lembram que em praticamente todas as sociedades humanas o processo de socialização $\ddot{i}$ isto é, de transformação de um indivíduo biológico em uma pessoa social - realiza-se através da constante interação entre duas dimensões. Uma é a socialização primária, vivida quase sempre no círculo familiar, parental, e de grupos de idade, sobretudo entre crianças e entre adolescentes. A outra é a socialização secundária, realizada para além da esfera interativa primária. Ela exige instituições especializadas em reprodução e transmissão do saber e dos valores. A escola e o sistema educacional público são, em nossa sociedade, o seu melhor exemplo.

\footnotetext{
4 Ver referência no conhecido livro: A construção social da realidade: tratado de sociologia do conhecimento. Petrópolis: Vozes, 1974. 247 p.
} 
De uma forma ou de outra, por razões utilitárias regidas pela necessidade ou por efeito de desejos humanos que transcendem a utilidade prática, a espécie humana cria e recria a si mesma e as diferentes instâncias do mundo em que vive. E, sendo nós uma espécie de seres que não podem viver a não ser socialmente, entre acordos, gestos solidários, alianças e conflitos, tudo o que nós, humanos, fazemos quando agimos, de um modo ou de outro é um compartilhar com os demais, com os diferentes ñnossos outrosò. Outros ora nos ensinam, ora conosco aprendem.

E essa troca inspira novos melhoramentos, novos engenhos e, conseqüentemente, novos símbolos. $\mathrm{E}$ ai, presenciamos o ir e vir de mensagens, de saberes, de comunicações e de informações que tanto preservam a tradição como geram as descobertas e inovações que, ao mesmo tempo, nos unem e nos diferenciam.

\section{Refletindo o conjunto: memória e cultura}

Dessa forma, cultura e memória se ligam e se complementam. Memória enquanto elo, enquanto fio condutor, enquanto linha de transmissão que permite que viveres, memórias-hábitos, imagens-lembranças, sejam re-existidas no tempo. A cultura em meio a isso é o conteúdo. É o que está na memória, o que está nas imagens, no cotidiano, no condicionamento. Ela pode ter se desenvolvido a partir da relação do homem com objetos, e pelo princípio da semelhança.

\footnotetext{
É difícil conceber como despertaria em uma consciência isolada o sentimento da identidade pessoal, talvez porque nos parece que um homem inteiramente só não poderia se lembrar de modo algum. Contudo, se admitimos que no mínimo não muda o ambiente exterior no qual estaria um ser assim, se ele não estiver sempre mudando de lugar, nada impediria que se habituasse pouco a pouco aos objetos materiais que o circundam e que se apresentam freqüentemente a seus olhos. Revendo os mesmos lugares, ele talvez recordará que já os viu e este poderia ser seu ponto de partida de um sentimento do eu. É claro, nem tudo é uniforme neste círculo material e segundo o acaso de seus impulsos, ele um dia irá para esse lado, em outro dia para aquele. Movimentando-se num círculo limitado e voltando muitas vezes sobre seus próprios passos na região, em que se desloca, nada o impede de ser mais sensível às semelhanças do que às diferenças. Todos esses objetos realmente se parecem, pelo fato de estarem mãos ou menos estritamente ligados em sua consciência. Ainda não é uma sociedade, mas o homem já pode sentir que é duplo, pois enquanto um grande número de suas impressões se sucede sem deixar traços, outros se agarram a objetos estáveis, ele deve perceber que em si contém dois seres ï um que está sempre mudando e não passa de (desaparecimento do passado) aparição breve e desaparecimento imediato que absolutamente não se conserva e não deixa traços... (HALBWARCHS, 2006. p.110)
}

Uma pedra que em formato afiado está sempre no mesmo lugar, que aos poucos é descoberta enquanto instrumento de corte. É um acontecer que se torna cultural, na medida em que a pedra se torna utensílio utilizado seguidamente. É cultural quando o ato de utilizar a pedra com o corte é ensinado a um outro e a um outro. Pois nesse ensinar, logo o grupo o utilizará, logo será um condicionamento. Um fazer sem o pensar, mas, um saber transmitido na prática. É cultural na medida em que define relação entre homem e natureza, ou homem e homem. É e perpetuado na medida em que passa pelo fio da memória e re-existe continuamente. 
A cultura é assim, o conteúdo das imagens, o conteúdo do que condiciona, do que nos torna socializáveis e compartilhantes entre os nossos. É o fluido que é transmitido pela memória, pela linha do tempo, que sobrevive de geração para geração em tempos e espaços que parecem vários, mas que podem ser apenas um. (HALBWACHS, 2006). Um único que não se define numa linha reta, tal como habituados estamos, mas, que acompanha o ritmo e a velocidade de cada um. Ou que se torna único ditado pela lógica do global, do comum. Dessa forma, cultura e memória se ligam e se complementam. Memória enquanto elo, enquanto fio condutor, e cultura enquanto conteúdo que perpetua.

\section{BIBLIOGRAFIA}

BERGER, Peter e LUCKMAN, Thomas. A construção social da realidade: tratado de sociologia do conhecimento. Petrópolis: Vozes, 1974.

BOSI, Ecléa. Memória e Sociedade: lembranças de velhos. São Paulo: Tao. 1979.

2003.

O tempo vivo da memória: ensaios de psicologia social. São Paulo: Ateliê.

Cultura Popular e Educação: salto para o futuro. In: SILVA, René Marc da Costa. Cultura Popular e Educação. Brasília: Ministério da Educação, Secretária de Educação a distância, 2008. p. 25-100.

Notas de aula da Disciplina Tópicos Especiais em Geografia: Cultura Popular e Memória Social, ministrada pelo Professor Carlos Rodrigues Brandão no segundo semestre de 2010.

O Saber, O cantar e O viver do povo. São José dos Campos: Centro de Estudos da Cultura Popular. Fundação Cultural Cassiano Ricardo. Cadernos de Foclore. 2009B.

EAGLETON, Terry. A idéia de cultural. São Paulo: Editora Unesp, 2005.

HALBWACHS, Maurice. A memória Coletiva. São Paulo: Centauro. 2006

LAPLANTINE, François. Aprender Antropologia. 9a edição. São Paulo, Editora Brasiliense. 1996

WILLIAMS, Raymond. Cultura. Rio de Janeiro: Paz e Terra, 1992.

Enviado para publicação em novembro de 2011.

Aceito para publicação em novembro de 2011. 